\title{
Chemoresistance in pancreatic cancer: Emerging concepts (Review)
}

\author{
MANU GNANAMONY ${ }^{1}$ and CHRISTOPHER S. GONDI ${ }^{1-3}$ \\ Departments of ${ }^{1}$ Internal Medicine, ${ }^{2}$ Surgery and ${ }^{3}$ Pathology, \\ University of Illinois College of Medicine at Peoria, Peoria, IL 61605, USA
}

Received March 23, 2016; Accepted January 17, 2017

DOI: $10.3892 / \mathrm{ol} .2017 .5777$

\begin{abstract}
Pancreatic cancer is one of the most lethal types of cancer in the world. The incidence of pancreatic cancer increases each year with no significant decrease in mortality. Pancreatic cancer is a complex disease, and this complexity is partly attributed to late diagnosis, an aggressive phenotype, environmental factors and lack of effective treatment options. Surgical resection followed by adjuvant chemotherapy is the treatment of choice for early stage cancer, whereas gemcitabine is the standard first line therapy for patients with advanced stage disease. Treatment regimens comprising folinic acid, 5-fluorouracil, irinotecan, oxaliplatin and nab-paclitaxel have demonstrated modest effects in improving median survival rates. A number of other chemotherapeutics are currently undergoing clinical trials as components of combination therapies with gemcitabine. An increasing number of novel molecular targets and cellular pathways are being identified, which highlights the complexity of this disease. The development of chemoresistance to gemcitabine is multifactorial and there exists an interplay between pancreatic cancer cells, the tumor microenvironment and cancer stem cells. These components appear to be governed by a complex network of non-coding RNAs such as micro RNAs and long non-coding RNAs. In the present study, studies describing previous research on the understanding of the factors associated with the development of chemoresistance to gemcitabine in pancreatic cancer are reviewed. A comprehensive understanding of the multiple pathways of chemoresistance is key to develop next generation therapeutics to pancreatic cancer.
\end{abstract}

Correspondence to: Dr Christopher S. Gondi, Department of Internal Medicine, University of Illinois College of Medicine at Peoria, 1 Illini Drive, Peoria, IL 61605, USA

E-mail: gondi@uic.edu

Key words: pancreatic cancer, gemcitabine, chemoresistance, cancer stem cells, tumor microenvironment

\section{Contents}

1. Introduction

2. Therapeutic management of pancreatic cancer

3. Chemoresistance

4. Mechanism of action of gemcitabine in cells

5. Gemcitabine resistance mechanisms

6. Future directions

7. Conclusions

\section{Introduction}

Pancreatic cancer is the fourth leading cause of cancer-associated mortality in the United States, and predicted to be the second leading cause of cancer related mortality by 2030 (1). The mortality rate is almost equal to the incidence rate and it was estimated that in 2015, almost 49,000 incident cases were diagnosed and there were almost 40,000 mortalities (2). Pancreatic cancer exhibits a 5-year survival rate of $7 \%$ for all stages (2). An increased life span, smoking, family history of cancer, obesity, chronic pancreatitis, diabetes and occupational hazards are some of the well-established risk factors for pancreatic cancer.

Almost $90 \%$ of pancreatic malignancies are pancreatic ductal adenocarcinomas (PDACs). The disease progresses asymptomatically in $80 \%$ of patients, and is usually detected in the advanced stages by which time it is non-resectable. Amongst the $10-15 \%$ of patients who present with resectable disease, $80 \%$ develop relapse within 2-3 years. Several factors such as a delay in diagnosis, the aggressiveness of the established tumors, lack of proper therapy and the development of drug resistance are attributed to the low survival rate. Despite numerous studies having been carried out, no significant progress has occurred in the previous two decades.

\section{Therapeutic management of pancreatic cancer}

Surgery followed by adjuvant therapy is the treatment of choice for patients who present with early stage disease. However, majority of patients present with locally advanced disease or metastatic disease and exhibit poor prognoses. Without any treatment, these patients only survive for 12-14 weeks (3). Gemcitabine is a standard chemotherapeutic drug and has 
been widely used as a first-line drug for patients with advanced staged pancreatic cancer. Patients treated with gemcitabine exhibited a significant improvement in the median overall survival rates (5.65 vs. 4.41 months) and 1-year survival rates (18 vs. $2 \%$ ) compared with 5-fluorouracil (5-FU) (4). In the previous decade, several phase III trials performed to examine the efficacy of various drugs either alone or in combination with gemcitabine resulted in modest successes (5). Gemcitabine in combination with nab-paclitaxel increased the median survival from 6.7 to 8.7 months and when administered with FOLFIRINOX (folinic acid, 5-FU, irinotecan, and oxaliplatin) treatment, the median survival rate increased from 6.8 to 11.2 months (5).

There are other recent reviews that describe, in detail, the current drugs undergoing clinical trials $(5,6)$. The present review will focus on the significant recent advances over the previous year in the development of chemoresistance, and the potential pathways and molecules that may be targeted to effectively improve the efficacy of therapy for pancreatic cancer.

\section{Chemoresistance}

The majority of studies examining chemoresistance in advanced pancreatic cancer focus on gemcitabine, as the data on the action of other drugs remain preliminary. It is uncertain why pancreatic cancer cells are more susceptible to gemcitabine compared with other anticancer drugs. Despite of this sensitivity, the majority of patients with pancreatic cancer develop resistance to gemcitabine, which means that the delineation of the mechanisms of gemcitabine chemoresistance is important. Several cellular factors such as human equilibrative nucleoside transporter 1 , human concentrative nucleoside transporter 1 and deoxycytidine kinase are involved in gemcitabine resistance mechanisms and have been investigated extensively $(6,7)$. The present review will focus on the gemcitabine resistance mechanisms that have been identified recently to augment the pre-existing data.

\section{Mechanism of action of gemcitabine in cells}

Gemcitabine, also termed 2',2'-difluoro-2'-deoxycytidine $(\mathrm{dFdC})$, is a deoxycytidine analog. Entry of gemcitabine into cells is mediated by human nucleoside transporters (7). Inside the cells, the pro-form of gemcitabine is phosphorylated to form the active triphosphate form of gemcitabine, $\mathrm{dFdC}$ triphosphate (dFdCTP) (7). The main mechanism of action of gemcitabine occurs through the direct inhibition of DNA synthesis (8): dFdCTP is incorporated into growing DNA strands by DNA polymerase, which results in the termination of DNA synthesis by a process termed 'masked chain termination' (7). Another mechanism of gemcitabine action is the inhibition of the enzymes required for deoxynucleotide metabolism (7). Gemcitabine has also demonstrated the ability to trigger apoptosis through caspase signaling (7).

\section{Gemcitabine resistance mechanisms}

The tumor protein (p)53 gene is frequently mutated in patients with PDAC. Gemcitabine stabilizes the expression of mutant p53 and the corresponding downstream targets cyclin-dependent kinase 1 and cyclin B1, resulting in hyperproliferation and chemoresistance (9) thus, mutant $\mathrm{p} 53$ contributes to gemcitabine resistance. The concomitant treatment of gemcitabine with the p53-reactivating molecules CP-31398 and recombining binding protein suppressor of hairless-interacting and tubulin associated protein resulted in an increased level of apoptosis and reduced growth rates (9). Hypoxia is another critical factor in tumor development and chemoresistance. Hypoxic cancer cells stabilize the transcription factor hypoxia-inducible factor- $1 \alpha(\mathrm{HIF}-1 \alpha)$ and activate nuclear factor $(\mathrm{NF})-\kappa \mathrm{B}$ leading to an epithelial-mesenchymal transition (EMT) phenotype characterized by an overexpression of vimentin and neural-cadherin (10). Hypoxia also results in the accumulation of lactate dehydrogenase-A, which assists in the maintenance of the hypoxic phenotype and increasing chemoresistance (11). Novel molecular targets and molecules that have been identified include: Protein tyrosine kinase-6 (12); vitamin D receptor (VDR) (13); mucin-1 (MUC1) (14); ormeloxifene that targets the sonic hedgehog pathway (15); sodium metaarsenite (KML001) that targets the epidermal growth factor receptor (EGFR) and matrix metalloproteinase (MMP) 2 (16); the quinazolinedione-based redox modulator QD232 that targets proto-oncogene tyrosine-protein kinase/focal adhesion kinase (FAK) and signal transducer and activator of transcription 3 phosphorylation (17); aspirin, which was revealed to reduce tumor growth and sensitize cells to gemcitabine (18); the curaxin CBL0137, which targets $\mathrm{NF}-\kappa \mathrm{B}$ and ribonucleotide reductase (19) and sepantronium bromide (YM155) (20-22), which inhibits the action of inhibitor of apoptosis protein family members (20), as summarized in Table I.

The development of chemoresistance in pancreatic cancer is multifactorial and may be attributed to the interplay between the tumor microenvironment, cancer stem cells (CSCs) and non-coding RNAs, as illustrated in Fig. 1.

Cancer stem cells. CSCs are a small subset of cancer cells hypothesized to be the driving force of tumor development. CSCs possess the ability to self-renew, initiate tumor development at distant sites and develop drug resistance. This has encouraged previous studies to understand the mechanisms that drive the formation of CSCs and to find ways to specifically inhibit them. A recent study suggests that CSCs exhibit elevated expression levels of c-Jun N-terminal kinases (JNK), which are essential for their maintenance and are important in developing chemoresistance to gemcitabine and 5-FU. The knockdown of JNK results in an increase of gemcitabine-induced reactive oxygen species production (23). Another recent study has revealed that extrinsic Wnt signaling confers cancer cell stemness on susceptible cells through the activation of the extracellular signal-regulated kinase (ERK) $1 / 2$ and EMT pathways, and is mediated by the Wnt enhancer R-spondin 2 (24). Retinoic acid (RA) has been demonstrated to reduce the mRNA expression of cancer stem cell-like markers cluster of differentiation (CD) 44, CD24, CD133 and aldehyde dehydrogenase 1 (ALDH1) (25). RA also increases the apoptotic activity of gemcitabine (25). ALDH1 expression is regulated by transforming growth factor (TGF)- $\beta$ in a SMAD family member 4-dependent manner (26). CSCs also express a high level of CD47, which communicates with signal 
Table I. Newly identified molecular targets and pathways for pancreatic cancer sensitization.

Markers/molecules

Targeted pathways, mechanism of action

PTK6, Inhibition of cell cycle and induced apoptosis

Vitamin D receptor, disrupting DNA repair

PTK6 siRNA

Vitamin D receptor

knockdown

MUC1 shRNA

Ormeloxifene

KML001

(sodium meta-arsenite)

QD232

Aspirin

CBL0137

YM155
MUC1, p42-44 MAPK, Akt, Bcl-2 and MMP13 pathways

SHH signaling pathway, Inhibition of stromal cell infiltration and invasion of tumor cells

EGFR and MMP2, Inhibition of cell proliferation, migration and invasion

Src/FAK and STAT3 phosphorylation, Decreases cell migration, invasion and induction of apoptosis

Reduced growth, invasion and sensitized cells to gemcitabine

$\mathrm{NF}-\mathrm{kB}$ and ribonucleotide reductase, Induces apoptosis and targets cancer stem cells

Induced apoptosis by inhibiting IAP family proteins

(Refs.)

PTK6, protein tyrosine kinase-6; siRNA, silencing RNA; MUC1, mucin-1; shRNA, short hairpin RNA; p42-44, tumor proteins 42-44; Akt, protein kinase B; Bcl-2, B-cell lymphoma 2; MMP13, matrix metalloproteinase 13; SHH, sonic hedgehog; EGFR, epidermal growth factor receptor; Src, proto-oncogene tyrosine-protein kinase Src; FAK, focal adhesion kinase; STAT3, signal transducer and activator of transcription 3; NF-kB, nuclear factor kB; IAP, inhibitor of apoptosis.

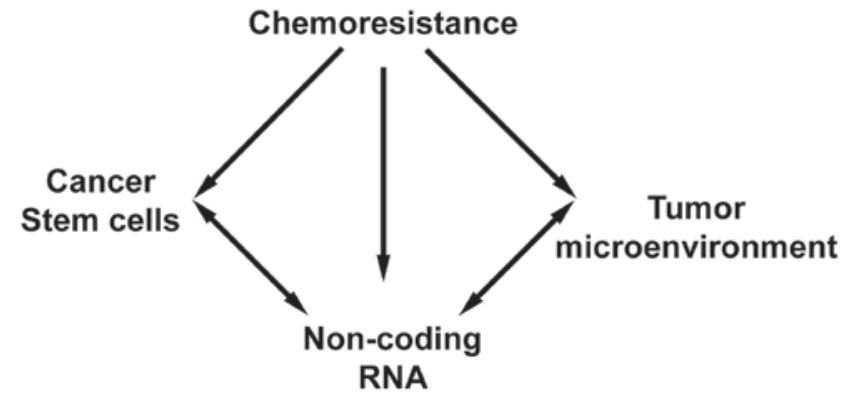

Figure 1. Factors associated with chemoresistance in pancreatic cancer. Chemoresistance in pancreatic cancer results from an interplay between the cancer cells, the tumor microenvironment, cancer stem cells and is intricately controlled by small non-coding RNAs like micro RNAs and long non-coding RNAs.

regulatory protein- $\alpha$ on the tumor associated macrophages of the tumor stroma and results in the evasion of phagocytosis. Blocking the expression of CD47 using anti-CD47 antibodies in combination with gemcitabine or Abraxane induced significant tumor regression (27).

Pancreatic CSCs exhibit low expression levels of microRNA (miR)-200c and overexpression of miR-200c with a concurrent increase in the expression levels of the EMT activator zinc finger E-box binding homeobox 1 (ZEB1) (28). ZEB1 regulates stemness and chemoresistance by the epigenetic silencing of miR-203. Treatment with mocetinostat, a class I histone deacetylase inhibitor, restored miR-203 function, which led to chemosensitization and a loss of stem cell characteristics (29). A previous study demonstrated that metastasis-associated lung adenocarcinoma transcript-1 (MALAT-1), a long non-coding (lnc) RNA, may increase proportions of pancreatic cancer stem cells, increase self-renewal and decrease chemosensitivity (30). Another study investigated the difference in microRNA
(miRNA/miR) profiles between pancreatic stem-like cells and normal cancer cells, and revealed that miR-21 and miR-221 exhibited higher expression levels in pancreatic cancer stem cells. A combination therapy of antisense nucleotides that targeting miR-21 and miR-221 demonstrated a reduction in the rates of cell proliferation, tumor growth and chemosensitivity to gemcitabine and 5-FU (31).

Tumor microenvironment. The tumor microenvironment is the interstitial tissue surrounding the cancer cells and consists of pancreatic stellate cells, fibroblasts, endothelial cells, inflammatory cells, nerve cells and other non-cellular components such as proteoglycans and fibrous proteins (32). These components of the stroma interact with the cancer cells and result in a desmoplastic reaction that induces migration, invasion and chemoresistance (33). The fibrous stroma surrounding the cancer core constitutes $90 \%$ of the tumor volume and impedes the proper delivery of chemotherapeutics to the cancer cells. Previous studies demonstrate that the depletion of stroma promoted cancer growth and progression, suggesting that the stroma possess factors that impede tumor growth $(34,35)$. Fibroblasts in stroma secrete soluble proteins that promote chemoresistance in cancer cells. Duluc et al (36) reported that the activation of somatostatin receptor 1 in cancer-associated fibroblasts by the SOM230 analogue pasireotide inhibited protein synthesis through the mechanistic target of rapamycin/4E-BP1 pathway, thereby increasing the efficacy of gemcitabine therapy.

Pancreatic stellate cells (PSCs). PSCs are one of the major constituents of the tumor stroma, and serve an important role in tumor growth. PSCs are present in a quiescent state in normal tissue, but upon activation by inflammatory signals such as TGF- $\beta 1$, become activated and present a myofibroblast-like 
phenotype (32). These activated PSCs secrete extracellular matrix (ECM) proteins including collagen, fibronectin and laminin, leading to the formation of a dense stroma matrix. Stellate cells affect tumor cell growth, maintenance and chemoresistance in pancreatic cancer cells. A previous study carried out using a co-culture of PSCs and pancreatic cancer cells demonstrated an increased resistance to gemcitabine through an increased expression of hairy and enhancer of split-1 (Hes1) through the Notch signaling pathway. The knockdown of either Hes1 or the Notch signaling pathway was revealed to reverse chemoresistance (37). PSCs secrete soluble stromal cell-derived factor- $1 \alpha$, which blocks gemcitabine-induced apoptosis in cancer cells by binding to their receptor $\mathrm{C}-\mathrm{X}-\mathrm{C}$ chemokine receptor type 4 and activating the FAK-protein kinase B (AKT) and ERK 1/2 signaling pathways (38). PSCs also express VDR, and their activation by VDR ligands has been demonstrated to regulate tumor stromal remodeling from an active to a quiescent state (39). A recent study has revealed that activated PSCs exhibit decreased expression levels of miR-29a and miR-29b, which is associated with an increased ECM deposition. An overexpression of either of these miRs reversed the process (40).

Immune cells. Immune cells infiltrate solid tumors and serve either a tumor promoting- or tumor-suppressing role. Immune cells in the stroma such as tissue-associated macrophages (TAMs) secrete an immunomodulatory antimicrobial peptide 18/LL-37 (hCAP-18/LL-37; cathelicidin antimicrobial peptide) that increases the expression levels of the pluripotency associated genes, the rate of self-renewal and tumorigenicity via formyl peptide receptor 2 and P2X purinoceptor 7 receptor-dependent mechanisms (41). TAMs have also been demonstrated to secrete an enzyme termed cytidine deaminase, which degrades the bio-active form of gemcitabine in cancer cells and thereby renders the cells chemoresistant (42). TAMs also secrete interferon (IFN)-stimulated gene 15 in response to IFN- $\beta$ secreted by CSCs and assists in the self-renewal process and sustained tumorigenicity (43), as summarized in Table II.

\section{Non-coding RNAs}

$m i R s$. miRs regulate the gene expression in the majority of biological processes in the cell, and therefore have been hypothesized to serve an important role in the chemoresistance to standard treatment regimens in pancreatic cancer. Numerous studies demonstrated that miRs are differentially expressed in a variety of types of cancer (44-50). A study examining the miR profile of gemcitabine-sensitive and resistant pancreatic cancer cell lines reported the presence of 33 differentially regulated miRs (44). Of these miRs, miR-497 was the most downregulated gene, and its upregulation resulted in the sensitization of the pancreatic cancer cells to gemcitabine and erlotinib (44). miR-33a overexpression has been demonstrated to sensitize pancreatic cancer cells to gemcitabine and inhibit tumor growth through the suppression of Pim-3 kinase expression (45). Incidentally, miR-33a was also reported to be downregulated in gemcitabine-resistant cells (44). miR-29a and miR-330-5p have been revealed to serve as tumor suppressors by downregulating MUC1 expression and sensitizing pancreatic
Table II. Summary of potential targets to be considered for chemosensitization.

\begin{tabular}{lcc}
\hline Drug target & $\begin{array}{c}\text { With/without } \\
\text { gemcitabine }\end{array}$ & (Refs.) \\
\hline Cancer stem cells & Yes & $(23-25,27)$ \\
JNK & No \\
R-Spondin 2/Wnt signaling & Yes \\
Retinoic acid & Yes \\
CD47 & \\
Pancreatic Stellate cells & With \\
Hes1/Notch signaling & With \\
SDF-1 $\alpha$ & No \\
VDR ligands & \\
Immune cells & \\
(Tumor associated macrophages) & & \\
18/LL-37 & No \\
Cytidine deaminase & No \\
IFN-stimulated factor ISG15 & No \\
\hline
\end{tabular}

JNK, c-Jun N-terminal kinase; CD47, cluster of differentiation 47; Hes1, hairy and enhancer of split-1; SDF-1 $\alpha$, stromal cell-derived factor $1 \alpha$; VDR, vitamin D receptor; IFN, interferon; ISG15, interferon-stimulated gene 15 .

Table III. miRNAs that are differentially regulated in pancreatic cancer.

\begin{tabular}{lccc}
\hline miRNA & $\begin{array}{c}\text { Pro/Anti- } \\
\text { oncogenic }\end{array}$ & Chemoresistance & (Refs.) \\
\hline miR-497 & Anti & + & $(43)$ \\
miR-33a & Anti & + & $(43,44)$ \\
miR-29a & Anti & + & $(45)$ \\
miR-330-5p & Anti & + & $(45)$ \\
miR-21 & Anti & + & $(46)$ \\
miR-17-92 & Anti & + & $(49)$ \\
$\operatorname{miR}-221$ & Pro & - & $(48)$ \\
$\operatorname{miR}-1246$ & Pro & - & $(47)$ \\
\hline
\end{tabular}

miRNA/miR, microRNA.

cancer cells to gemcitabine (46). Another study demonstrated that miR-21 overexpression results in an increased sensitivity to gemcitabine via a decrease in the expression levels of the $p 85 \alpha$ subunit of phosphatidylinositol-4,5-biphostphate 3-kinase (47). miR-1246 has been revealed to increase stemness and induce drug resistance in pancreatic cancer cell lines (48). Similarly, miR-221/222 was demonstrated to induce pancreatic cancer progression through the regulation of MMPs (49), indicating that miRs may be pro- and anti-oncogenic. Another study has revealed that chemoresistant pancreatic cancer stem cells exhibit lower expression levels of miR-17-92 compared with chemosensitive cancer 
stem cells. The overexpression of this miRNA reduced the CSC self-renewal capacity of the resistant CSCs, and sensitized them to chemotherapy (50), as summarized in Table III.

lncRNAs. IncRNAs are a group of non-coding RNAs that alter gene expression and also serve as miR sponges. Like 'cleaning sponges' these lncRNAs have been demonstrated to mop up multiple regulatory RNAs and behave as possible epigenetic regulators (51-54). The role of lncRNAs in the development of cancer remains incompletely characterized, yet several studies indicate a role in epigenetic regulatory mechanisms (55). Next generation sequencing technology has identified differential expression levels of several lncRNAs in PDAC samples compared with normal tissues (56). A recent microarray profiling study identified the homeobox A transcript at the distal tip (HOTTIP) as an important IncRNA that is upregulated in PDAC. The knockdown of HOTTIP reduced the rates of cell proliferation and sensitized pancreatic cancer cells to gemcitabine (57).

\section{Future directions}

The ultimate aim of cancer therapy is to specifically target and destroy tumor cells, and chemoresistance is the major hurdle to achieving this. The poor survival rate of the standard treatment drug gemcitabine has prompted studies investigating combination therapies to increase the efficacy of the drug. A major disadvantage of the previous studies examining drug resistance in patients with pancreatic cancer is the usage of agents targeting single molecules or pathways. A multidirectional approach that targets multiple aspects of the cancer cell such as the tumor cell microenvironment and immune cells is required.

The identification of the novel roles of non-coding RNAs in tumor development has identified avenues for the development of combination drugs. Non-coding RNAs, particularly miRNAs, and their control on the stages of tumor development are well established. Several miRNAs that exhibit a tumor suppressor function are downregulated in advanced tumors, and it is necessary that future drug combinations include miRNA mimics as targets. Although numerous studies investigating the role of miRNAs have been performed, more large scale studies on lncRNAs are necessary. An important goal of future studies is to identify the expression levels of large non-coding RNAs that may serve as potential biomarkers of chemoresistance. The identification of the probable functional role of these lncRNAs in modulating the effect of gemcitabine on target cells is also an important clinical question.

Circular RNAs (circRNA) are another under-studied factor that may serve an important role in the treatment of cancer. Previous studies have identified natural endogenous circRNA that possesses conserved miR target sequences and acts as miR sponges $(58,59)$, which mop up other regulatory RNAs (51-54). Hansen et al have identified an endogenous circRNA termed ciRS-7 that has more than 70 selectively conserved miR-7 target sites and have coined the term miR sponges. CiRS-7 has been shown to suppress miR-7 activity (58). circRNAs are also more stable compared with linear miR, and this phenomenon may be exploited to artificially target oncogenic miRs (60).

\section{Conclusion}

Current chemotherapeutics for the treatment of advanced pancreatic cancer are not successful. The available drugs often result in high toxicity levels and the development of drug resistance. Numerous drug prospects targeting molecular pathways and specific cellular proteins in pancreatic cancer cells and the surrounding pancreatic stellate, and immune cells are being developed to increase the quality of life of patients with pancreatic cancer. Previous studies discussed in the present review have demonstrated the importance of miRNAs as central factors that may serve a vital role in the development of chemoresistance. The role of other non-coding RNAs such as lncRNA and circRNAs remain uncharacterized, and may be important components for understanding the mechanisms of gemcitabine resistance. Drug resistance in pancreatic cancer is multifaceted and future studies targeting different pathways and targets are required to understand and successfully treat pancreatic cancer.

\section{Acknowledgements}

The present study was supported by the Department of Internal Medicine, University of Illinois College of Medicine at Peoria, IL; McElroy Foundation (grant no. 2014-06298), Springfield IL and The Theresa Tracy Strive to Survive Foundation, East Peoria, IL 61611.

\section{References}

1. Rahib L, Smith BD, Aizenberg R, Rosenzweig AB, Fleshman JM and Matrisian LM: Projecting cancer incidence and deaths to 2030: The unexpected burden of thyroid, liver and pancreas cancers in the united states. Cancer Res 74: 2913-2921, 2014.

2. Siegel RL, Miller KD and Jemal A: Cancer statistics, 2015. CA Cancer J Clin 65: 5-29, 2015.

3. Carmichael J, Fink U, Russell RC, Spittle MF, Harris AL, Spiessi G and Blatter J: Phase II study of gemcitabine in patients with advanced pancreatic cancer. Br J Cancer 73: 101-105, 1996.

4. Burris HA III, Moore MJ, Andersen J, Green MR, Rothenberg ML, Modiano MR, Cripps MC, Portenoy RK, Storniolo AM, Tarassoff $\mathrm{P}$, et al: Improvements in survival and clinical benefit with gemcitabine as first-line therapy for patients with advanced pancreas cancer: A randomized trial. J Clin Oncol 15: 2403-2413, 1997.

5. Garrido-Laguna I and Hidalgo M: Pancreatic cancer: From state-of-the-art treatments to promising novel therapies. Nat Rev Clin Oncol 12: 319-334, 2015.

6. Rossi ML, Rehman AA and Gondi CS: Therapeutic options for the management of pancreatic cancer. World J Gastroenterol 20: 11142-11159, 2014.

7. de Sousa Cavalcante L and Monteiro G: Gemcitabine: Metabolism and molecular mechanisms of action, sensitivity and chemoresistance in pancreatic cancer. Eur J Pharmacol 741: 8-16, 2014.

8. Huang P, Chubb S, Hertel LW, Grindey GB and Plunkett W: Action of 2',2'-difluorodeoxycytidine on DNA synthesis. Cancer Res 51: 6110-6117, 1991.

9. Fiorini C, Cordani M, Padroni C, Blandino G, Di Agostino S and Donadelli M: Mutant p53 stimulates chemoresistance of pancreatic adenocarcinoma cells to gemcitabine. Biochim Biophys Acta 1853: 89-100, 2015.

10. Cheng ZX, Wang DW, Liu T, Liu WX, Xia WB, Xu J, Zhang YH, Qu YK, Guo LQ, Ding L, et al: Effects of the HIF-1 $\alpha$ and NF-kB loop on epithelial-mesenchymal transition and chemoresistance induced by hypoxia in pancreatic cancer cells. Oncol Rep 31: 1891-1898, 2014.

11. Maftouh M, Avan A, Sciarrillo R, Granchi C, Leon LG, Rani R, Funel N, Smid K, Honeywell R, Boggi U, et al: Synergistic interaction of novel lactate dehydrogenase inhibitors with gemcitabine against pancreatic cancer cells in hypoxia. Br J Cancer 110: 172-182, 2014. 
12. Ono $\mathrm{H}$, Basson MD and Ito $\mathrm{H}$ : PTK6 potentiates gemcitabine-induced apoptosis by prolonging S-phase and enhancing DNA damage in pancreatic cancer. Mol Cancer Res 13: 1174-1184, 2015.

13. Bhattacharjee V, Zhou Y and Yen TJ: A synthetic lethal screen identifies the vitamin $\mathrm{D}$ receptor as a novel gemcitabine sensitizer in pancreatic cancer cells. Cell Cycle 13: 3839-3856, 2014.

14. Tréhoux S, Duchêne B, Jonckheere N and Van Seuningen I: The MUC1 oncomucin regulates pancreatic cancer cell biological properties and chemoresistance. Implication of p42-44 MAPK, akt, bcl-2 and MMP13 pathways. Biochem Biophys Res Commun 456: 757-762, 2015.

15. Khan S, Ebeling MC, Chauhan N, Thompson PA, Gara RK, Ganju A, Yallapu MM, Behrman SW, Zhao H, Zafar N, et al Ormeloxifene suppresses desmoplasia and enhances sensitivity of gemcitabine in pancreatic cancer. Cancer Res 75: 2292-2304, 2015.

16. Yang MH, Lee KT, Yang S, Lee JK, Lee KH and Rhee JC: KML001 enhances anticancer activity of gemcitabine against pancreatic cancer cells. Anticancer Res 35: 183-189, 2015.

17. Pathania D, Kuang Y, Sechi M and Neamati N: Mechanisms underlying the cytotoxicity of a novel quinazolinedione-based redox modulator, QD232, in pancreatic cancer cells. Br J Pharmacol 172: 50-63, 2015

18. Zhang Y, Liu L, Fan P, Bauer N, Gladkich J, Ryschich E, Bazhin AV, Giese NA, Strobel O, Hackert T, et al: Aspirin counteracts cancer stem cell features, desmoplasia and gemcitabine resistance in pancreatic cancer. Oncotarget 6: 9999-10015, 2015.

19. Burkhart C, Fleyshman D, Kohrn R, Commane M, Garrigan J, Kurbatov V, Toshkov I, Ramachandran R, Martello L and Gurova KV: Curaxin CBL0137 eradicates drug resistant cancer stem cells and potentiates efficacy of gemcitabine in preclinical models of pancreatic cancer. Oncotarget 5: 11038-11053, 2014.

20. Zhao X, Puszyk WM, Lu Z, Ostrov DA, George TJ, Robertson KD and Liu C: Small molecule inhibitor YM155-mediated activation of death receptor 5 is crucial for chemotherapy-induced apoptosis in pancreatic carcinoma. Mol Cancer Ther 14: 80-89, 2015.

21. Huang YT, Cheng CC, Lin TC, Chiu TH and Lai PC: Therapeutic potential of sepantronium bromide YM155 in gemcitabine-resistant human urothelial carcinoma cells. Oncol Rep 31: 771-780, 2014.

22. Yoon DH, Shin JS, Jin DH, Hong SW, Jung KA, Kim SM, Hong YS, Kim KP, Lee JL, Suh C, et al: The survivin suppressant YM155 potentiates chemosensitivity to gemcitabine in the human pancreatic cancer cell line MiaPaCa-2. Anticancer Res 32: 1681-1688, 2012.

23. Suzuki S, Okada M, Shibuya K, Seino M, Sato A, Takeda H Seino S, Yoshioka T and Kitanaka C: JNK suppression of chemotherapeutic agents-induced ROS confers chemoresistance on pancreatic cancer stem cells. Oncotarget 6: 458-470, 2015.

24. Ilmer M, Boiles AR, Regel I, Yokoi K, Michalski CW, Wistuba II, Rodriguez J, Alt E and Vykoukal J: RSPO2 enhances canonical wnt signaling to confer stemness-associated traits to susceptible pancreatic cancer cells. Cancer Res 75: 1883-1896, 2015.

25. Herreros-Villanueva M, Er TK and Bujanda L: Retinoic acid reduces stem cell-like features in pancreatic cancer cells. Pancreas 44: 918-924, 2015.

26. Hoshino Y, Nishida J, Katsuno Y, Koinuma D, Aoki T, Kokudo N Miyazono K and Ehata S: Smad4 decreases the population of pancreatic cancer-initiating cells through transcriptional repression of ALDH1A1. Am J Pathol 185: 1457-1470, 2015.

27. Cioffi M, Trabulo S, Hidalgo M, Costello E, Greenhalf W, Erkan M, Kleeff J, Sainz B Jr and Heeschen C: Inhibition of CD47 effectively targets pancreatic cancer stem cells via dual mechanisms. Clin Cancer Res 21: 2325-2337, 2015.

28. Ma C, Ding Y, Yu W, Wang Q, Meng B and Huang T: microRNA-200c overexpression plays an inhibitory role in human pancreatic cancer stem cells by regulating epithelial-mesenchymal transition. Minerva Med 106: 193-202, 2015.

29. Meidhof S, Brabletz S, Lehmann W, Preca BT, Mock K, Ruh M, Schüler J, Berthold M, Weber A, Burk U, et al: ZEB1-associated drug resistance in cancer cells is reversed by the class I HDAC inhibitor mocetinostat. EMBO Mol Med 7: 831-847, 2015

30. Jiao F, Hu H, Han T, Yuan C, Wang L, Jin Z, Guo Z and Wang L: Long noncoding RNA MALAT-1 enhances stem cell-like phenotypes in pancreatic cancer cells. Int J Mol Sci 16: 6677-6693, 2015 .
31. Zhao Y, Zhao L, Ischenko I, Bao Q, Schwarz B, Nieß H, Wang Y, Renner A, Mysliwietz J, Jauch KW, et al: Antisense inhibition of microRNA-21 and microRNA-221 in tumor-initiating stem-like cells modulates tumorigenesis, metastasis, and chemotherapy resistance in pancreatic cancer. Target Oncol 10: 535-548, 2015.

32. Moir JA, Mann J and White SA: The role of pancreatic stellate cells in pancreatic cancer. Surg Oncol 24: 232-238, 2015.

33. Schober M, Jesenofsky R, Faissner R, Weidenauer C, Hagmann W, Michl P, Heuchel RL, Haas SL and Löhr JM: Desmoplasia and chemoresistance in pancreatic cancer. Cancers (Basel) 6: 2137-2154, 2014.

34. Rhim AD, Oberstein PE, Thomas DH, Mirek ET, Palermo CF, Sastra SA, Dekleva EN, Saunders T, Becerra CP, Tattersall IW, et al: Stromal elements act to restrain, rather than support, pancreatic ductal adenocarcinoma. Cancer Cell 25: 735-747, 2014.

35. Özdemir BC, Pentcheva-Hoang T, Carstens JL, Zheng X, Wu CC, Simpson TR, Laklai H, Sugimoto H, Kahlert C, Novitskiy SV, et al: Depletion of carcinoma-associated fibroblasts and fibrosis induces immunosuppression and accelerates pancreas cancer with reduced survival. Cancer Cell 25: 719-734, 2014.

36. Duluc C, Moatassim-Billah S, Chalabi-Dchar M, et al.: Pharmacological targeting of the protein synthesis mTOR/4EBP1 pathway in cancer-associated fibroblasts abrogates pancreatic tumour chemoresistance. EMBO Mol Med 7: 735-53, 2015.

37. Cao F, Li J, Sun H, Liu S, Cui Y and Li F: HES 1 is essential for chemoresistance induced by stellate cells and is associated with poor prognosis in pancreatic cancer. Oncol Rep 33: 1883-1889, 2015.

38. Zhang H, Wu H, Guan J, Wang L, Ren X, Shi X, Liang Z and Liu T: Paracrine SDF-1 $\alpha$ signaling mediates the effects of PSCs on GEM chemoresistance through an IL-6 autocrine loop in pancreatic cancer cells. Oncotarget 6: 3085-3097, 2015.

39. Sherman MH, Yu RT, Engle DD, Ding N, Atkins AR, Tiriac H, Collisson EA, Connor F, Van Dyke T, Kozlov S, et al: Vitamin D receptor-mediated stromal reprogramming suppresses pancreatitis and enhances pancreatic cancer therapy. Cell 159: 80-93, 2014.

40. Kwon JJ, Nabinger SC, Vega Z, Sahu SS, Alluri RK, Abdul-Sater Z, Yu Z, Gore J, Nalepa G, Saxena R, et al: Pathophysiological role of microRNA-29 in pancreatic cancer stroma. Sci Rep 5: 11450, 2015.

41. Sainz B Jr, Alcala S, Garcia E, Sanchez-Ripoll Y, Azevedo MM, Cioffi M, Tatari M, Miranda-Lorenzo I, Hidalgo M, Gomez-Lopez G, et al: Microenvironmental hCAP-18/LL-37 promotes pancreatic ductal adenocarcinoma by activating its cancer stem cell compartment. Gut 64: 1921-1935, 2015.

42. Amit M and Gil Z: Macrophages increase the resistance of pancreatic adenocarcinoma cells to gemcitabine by upregulating cytidine deaminase. Oncoimmunology 2: e27231, 2013.

43. Sainz B Jr, Martín B, Tatari M, Heeschen C and Guerra S: ISG15 is a critical microenvironmental factor for pancreatic cancer stem cells. Cancer Res 74: 7309-7320, 2014

44. Xu J, Wang T, Cao Z, Huang H, Li J, Liu W, Liu S, You L, Zhou L, Zhang T and Zhao Y: MiR-497 downregulation contributes to the malignancy of pancreatic cancer and associates with a poor prognosis. Oncotarget 5: 6983-6993, 2014.

45. Liang C, Yu XJ, Guo XZ, Sun MH, Wang Z, Song Y, Ni QX, Li HY, Mukaida N and Li YY: MicroRNA-33amediated downregulation of pim-3 kinase expression renders human pancreatic cancer cells sensitivity to gemcitabine. Oncotarget 6: 14440-14445, 2015.

46. Trehoux S, Lahdaoui F, Delpu Y, Renaud F, Leteurtre E, Torrisani J, Jonckheere N and Van Seuningen I: Micro-RNAs miR-29a and miR-330-5p function as tumor suppressors by targeting the MUC1 mucin in pancreatic cancer cells. Biochim Biophys Acta 1853: 2392-2403, 2015.

47. Toste PA, Li L, Kadera BE, Nguyen AH, Tran LM, Wu N, Madnick DL, Patel SG, Dawson DW and Donahue TR: p85a is a microRNA target and affects chemosensitivity in pancreatic cancer. J Surg Res 196: 285-293, 2015.

48. Hasegawa S, Eguchi H, Nagano H, Konno M, Tomimaru Y, Wada H, Hama N, Kawamoto K, Kobayashi S, Nishida N, et al: MicroRNA-1246 expression associated with CCNG2-mediated chemoresistance and stemness in pancreatic cancer. $\mathrm{Br} \mathrm{J}$ Cancer 111: 1572-1580, 2014.

49. Xu Q, Li P, Chen X, Zong L, Jiang Z, Nan L, Lei J, Duan W, Zhang D, Li X, et al: miR-221/222 induces pancreatic cancer progression through the regulation of matrix metalloproteinases. Oncotarget 6: 14153-14164, 2015. 
50. Cioffi M, Trabulo SM, Sanchez-Ripoll Y, Miranda-Lorenzo I, Lonardo E, Dorado J, Reis Vieira C, Ramirez JC, Hidalgo M, Aicher A, et al: The miR-17-92 cluster counteracts quiescence and chemoresistance in a distinct subpopulation of pancreatic cancer stem cells. Gut 64: 1936-1948, 2015.

51. Migault M, Donnou-Fournet E, Galibert MD and Gilot D: Definition and identification of small RNA sponges: Focus on miRNA sequestration. Methods pii: S1046-2023 30221-3, 2016

52. Li TR, Jia YJ, Wang Q, Shao XQ and Lv RJ: Circular RNA: A new star in neurological diseases. Int J Neurosci 1-9, 2016 (Epub ahead of print)

53. Qu S, Zhong Y, Shang R, Zhang X, Song W, Kjems J and Li H: The emerging landscape of circular RNA in life processes. RNA Biol 1-8, 2016 (Epub ahead of print).

54. Meng X, Li X, Zhang P, Wang J, Zhou Y and Chen M: Circular RNA: An emerging key player in RNA world. Brief Bioinform pii: bbw045: 2016 (Epub ahead of print).

55. Huarte $M$ and Rinn JL: Large non-coding RNAs: Missing links in cancer? Hum Mol Genet 19: R152-R161, 2010.
56. Müller S, Raulefs S, Bruns P, Afonso-Grunz F, Plötner A, Thermann R, Jäger C, Schlitter AM, Kong B, Regel I, et al: Next-generation sequencing reveals novel differentially regulated mRNAs, lncRNAs, miRNAs, sdRNAs, and a piRNA in pancreatic cancer. Mol Cancer 14: 94, 2015

57. Li Z, Zhao X, Zhou Y, Liu Y, Zhou Q, Ye H, Wang Y, Zeng J, Song Y, Gao W, et al: The long non-coding RNA HOTTIP promotes progression and gemcitabine resistance by regulating HOXA13 in pancreatic cancer. J Transl Med 13: 84, 2015.

58. Hansen TB, Jensen TI, Clausen BH, Bramsen JB, Finsen B, Damgaard CK and Kjems J: Natural RNA circles function as efficient microRNA sponges. Nature 495: 384-388, 2013.

59. Li F, Zhang L, Li W, Deng J, Zheng J, An M, Lu J and Zhou Y: Circular RNA ITCH has inhibitory effect on ESCC by suppressing the wnt/ $\beta$-catenin pathway. Oncotarget 6: 6001-6013, 2015.

60. Enuka Y, Lauriola M, Feldman ME, Sas-Chen A, Ulitsky I and Yarden Y: Circular RNAs are long-lived and display only minimal early alterations in response to a growth factor. Nucleic Acids Res 44: 1370-1383, 2016. 